\title{
Battle Against Solid Waste: Contribution of University Belt Barangays Towards Clean and Disaster-Prepared City
}

\author{
Fantonalgo $\mathrm{RN}^{1,2,3,4}$, Failanga $\mathrm{JN}^{5}$, Argañosa $\mathrm{MH}^{6}$, Bautista $\mathrm{RIT}^{4}$, Fajardo $\mathrm{RL}^{4}$, Ocampo $\mathrm{CM}^{4}$, Dalangin $\mathrm{IJ}^{4}$, Torres \\ RDL $^{4}$ and Perez JWD ${ }^{4}$
}

${ }^{1}$ Department of Biology, College of Arts and Sciences, Miriam College, Philippines

${ }^{2}$ Environmental Science Department, School of Science and Engineering, Ateneo de Manila University, Philippines

${ }^{3}$ Marine Science Institute, College of Science, University of the Philippines Diliman, Philippines

${ }^{4}$ Faculty of Natural Sciences and Research, Senior High School Department, College of Education, University of the East, Philippines

${ }^{5}$ Iloilo Science and Technology University-Miagao Campus, Philippines

${ }^{6}$ Iloilo Science and Technology University-Main Campus, Philippines

*Corresponding author: Fantonalgo RN, Department of Biology, College of Arts and Sciences, Miriam College, Quezon City, Philippines

\begin{abstract}
Solid waste is one of the major problems in the urban communities due to congestion and improper garbage disposal. This problem may lead to some health and disaster-related issues. University Belt Area (UBA), a congested place in Manila City, Philippines generate tons of solid waste materials daily. Given this condition, it is significant to know the response of the local government units (LGUs) in addressing this type of problem. Thus, this study investigated the solid waste management programs (SWMP) implemented by UBA barangays and its problems encountered in implementing the said programs. The awareness of the residents on SWMP and their suggestions for effective implementation of these programs were also determined. An in-depth interview was conducted among barangay officials. Small group discussion (SGD) was conducted among the selected residents. Thematic analysis was used to interpret the qualitative data while descriptive statistical tools were used to analyze the quantitative data. Findings revealed that programs implemented by ten barangays in UBA are categorized into educational, infrastructure, waste reduction, and regular cleaning activity. These programs are known to most of the residents who participated in the study. In the process of implementation, the LGUs are facing some constraints. These constraints include lack of discipline among the residents, lack of funds, irregular collection of waste materials, location of the barangay, and poor segregation practices. To effectively implement the afore-mentioned programs, the residents suggested some important recommendations. These encompass implementation of the appropriate barangay resolutions, raising public awareness, and imposition of penalties for the violators. Stakeholders should provide strong support for SWM agenda of UBA barangays. Policy makers should consider these data to formulate sound policies which can address the problems on solid waste. The barangay council should review Republic Act 9003 and consider collaboration with Ferris Wheel Project for better implementation of the programs.
\end{abstract}

Keywords: Barangays; Solid waste; Solid waste management programs; University belt area; Urbanized areas

\section{Introduction}

Every day the world is getting more urbanized. The rate of urbanization is increasing at an alarming rate. United Nations Department of Economic and Social Affairs (UNDESA) reported that $34 \%$ of the world's total population in 1960 was living in the urban centers. In 2014, this rate increased to 54\% [1]. This increase in urban population is brought by the natural increase due high fertility rate of the urban population and rapid rural to urban migration [2]. The rapid rate of migration is attributed to the pull factors inherent to the urban environment itself [3] like better job opportunities, access to health and educational facilities, and high standard of living. University Belt (U-Belt) area (Figure 1) in Manila, Philippines (Figure 2) is an area where colleges and universities are concentrated, hence the name implies. This area is the home of more 
than fifty higher educational institutions. The Central University Belt (CUBE) area is a seat for twenty universities and colleges. As Filipinos put a high regard for quality and responsive education, population over in this place has increased tremendously. This rise in population then is considered as contributing factors in the escalation of the amount of waste materials generated in the urban setting. According to National Solid Waste Management Commission Reports (2015). the estimated the amount of solid waste generated in 2010 in Manila City alone was 2,990,814 metric tons. In 2014, this figure increased to 3,595, 593 metric tons. There is, however, no specific information that pertains to the case of U-Belt area.

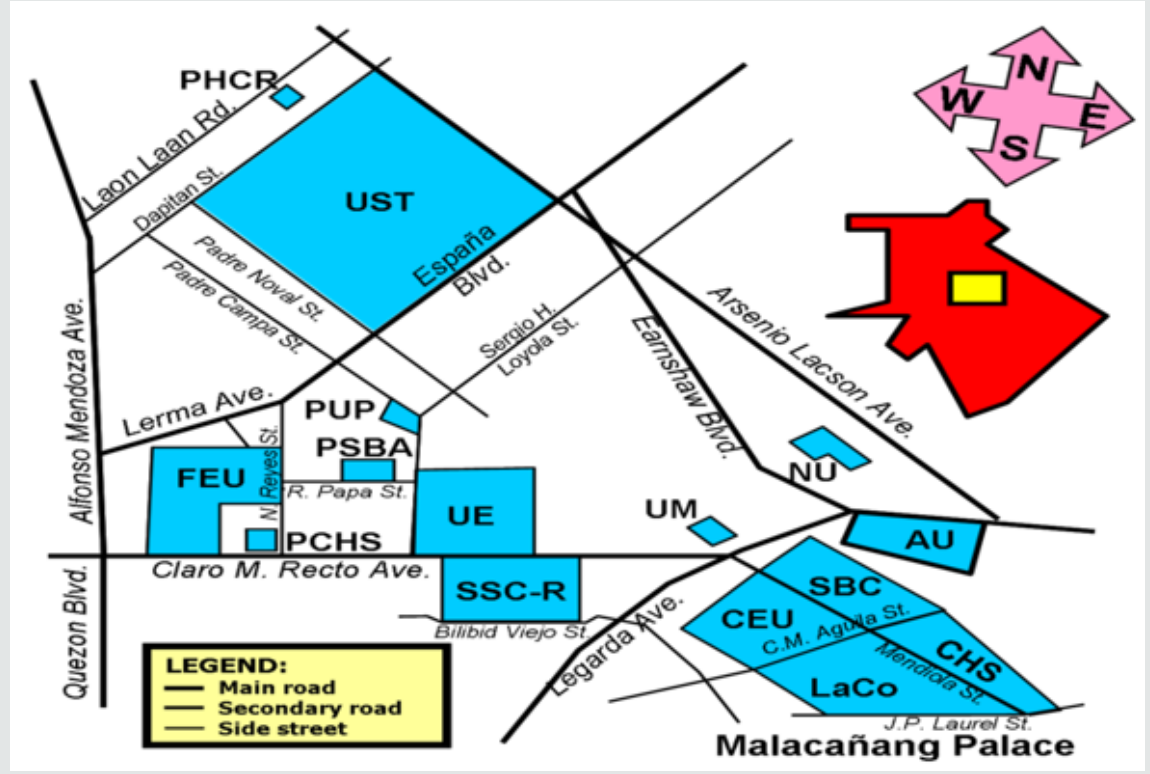

Figure 1: Vicinity Map of the U-Belt Area Manila, Philippines [23].

(Source: http:/ / en.wikipilipinas.org/images/4/42/UBelt.png)

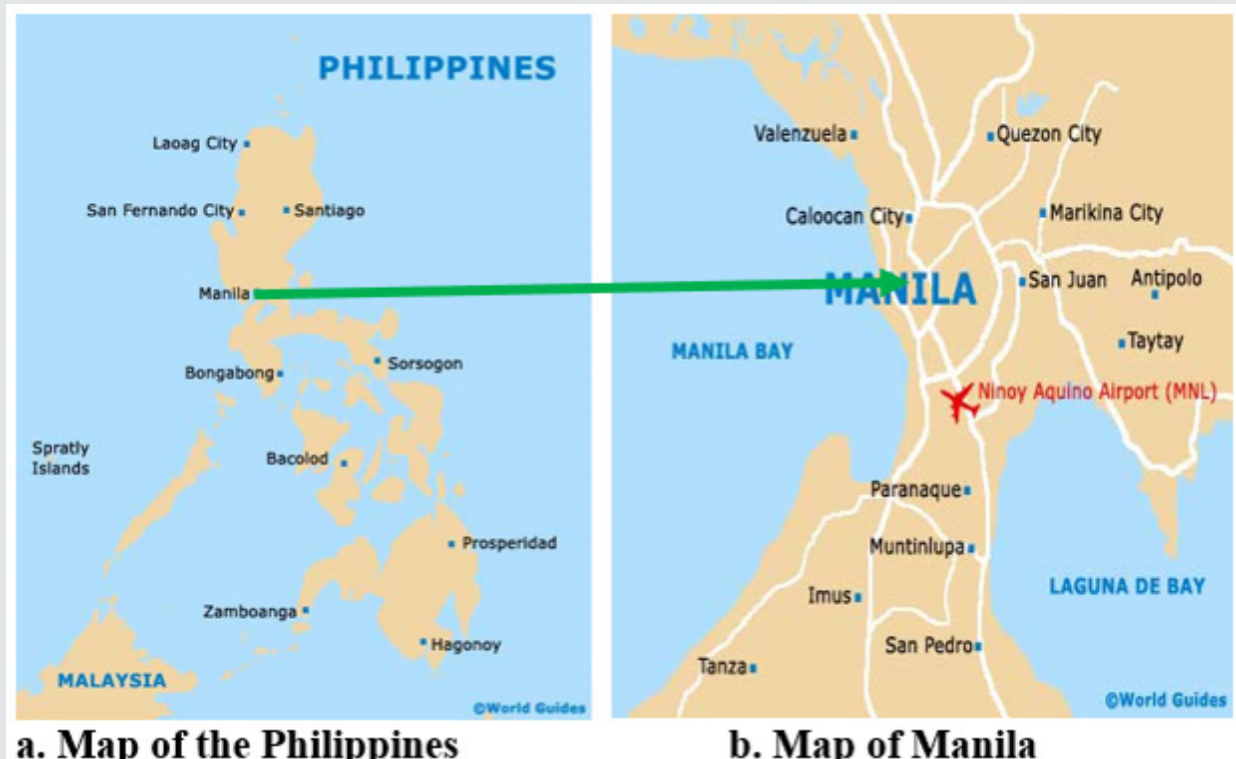

Figure 2: Map of the Philippines showing City of Manila [21,22].

Source: http:/ / www.world-guides.com/asia/philippines/national-capital region/manila/manila_maps.html

The rise in population in the U-Belt area also resulted to the emergence of additional commercial establishments, dormitories, and other infrastructure development. This infrastructure development resulted to changes in the land use and the increase in the urban surface sealing which increases the amount of surface run-off and decreases the ground water recharge [4].
This condition serves as a challenge to the Local Government Units (LGUs) on how to deal with this problem. The problems on improper waste management and high percentage of impermeable land make U-Belt area highly vulnerable to the devastating effects of flood. High amount of waste materials and improper disposal of these items make people highly prone to the diseases (National 
Solid Waste Management Commission Reports, 2015) [5]. From the prevailing condition of this place, the researchers came up with the framework on the goals of the implementation of solid waste management programs in U-Belt area (Figure 3). The current modified framework focuses on how the dirty, disaster-prone, and disorder U-Belt area can be converted into clean, disaster-prepared and orderly place (Figure 1). This framework was modified from the framework of Discipulo [6] on urban renewal study.
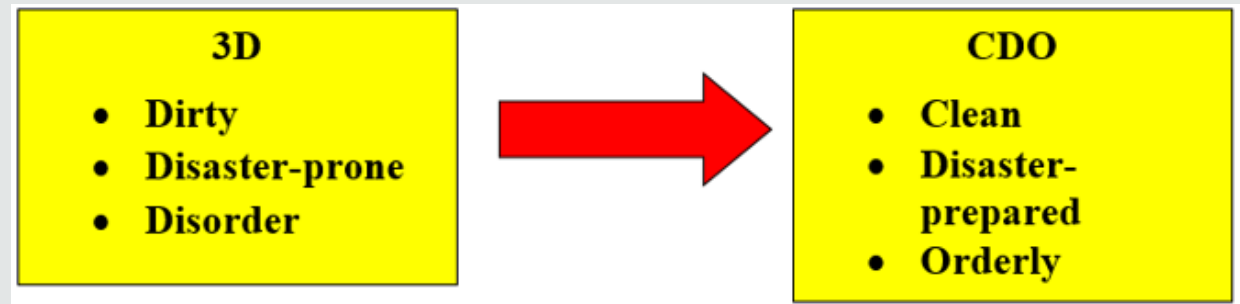

Figure 3: Conceptual Framework on the Goals of the Implementation of Solid Waste Management Programs in U-Belt Area.

From the existing problems on solid waste management in the U-Belt area, this study investigated the contribution of the U-Belt barangays towards a clean and disaster-prepared city. Specifically, this study determined the solid waste management programs implemented by the barangays around the University Belt, identified the problems encountered by the communities pertaining to the implementation of the programs, determined the awareness of the residents in the said programs, and identified the suggestions of the residents for effective solid waste management programs implementation. Data obtained from this study is vital in policy making and urban planning of LGUs. This will also agitate the stakeholders to support and participate in the program implementation.

\section{Materials and Methods}

\section{Research design}

The research design employed both descriptive and qualitative approaches. Qualitative research aims to interpret meanings, descriptions, and symbols [7]. The goals of this type of research are to provide answers to the why's and how's. On the other hand, descriptive approach was used to describe characteristics of the population being studied [8]. This approach answers the question of "what" in the study. Objectives 2 and 4 were answered using qualitative approach while objective 3 was answered using descriptive method. Both qualitative and descriptive approaches were used to answer objective 1 .

\section{Research locale}

The study was conducted in the U-Belt area. The name was given to this area because of the high concentration of the colleges and universities in this place. Originally, this name was given only to San Miguel district but technically it includes the nearby districts such as Quiapo, Santa Cruz. This area covers Mendiola Street, Morayta Street (now Nicanor B. Reyes Street), eastern end of Azcarraga Street (now Recto Avenue), Legarda Street, western end of España Boulevard, and the different side streets (Figure 4). This study covers the 10 barangays as given in Table 1 .

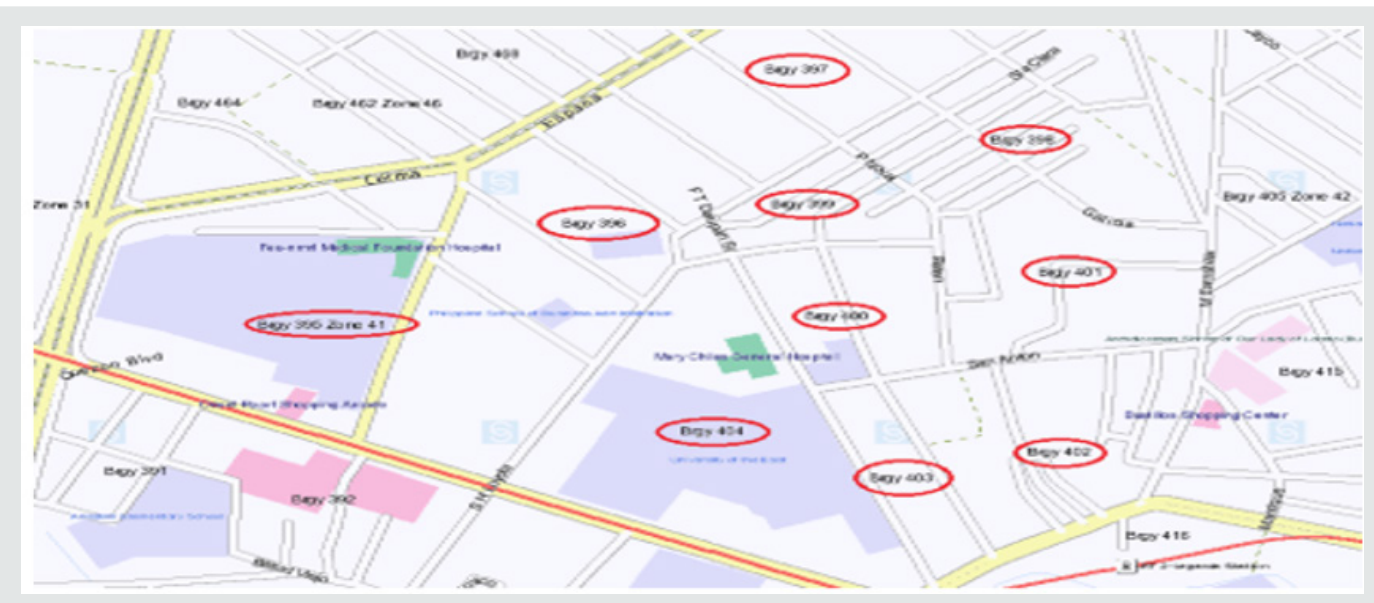

Figure 4: Barangays found in the University Belt, Area, Manila, Philippines [24].

Source: http:/ / www.mapcentral.ph/ 
Table 1: Number of participants and date of discussion during the small group discussion in the selected barangays in the U-Belt areas.

\begin{tabular}{|c|c|c|c|}
\hline Small Group Discussion Number & Place of Discussion & Number of Participants & Date of Discussion \\
\hline 1 & Brgy. 395 & 6 & September 09, 2017 \\
\hline 2 & Brgy. 395 & 4 & September 09, 2017 \\
\hline 3 & Brgy. 396 & 3 & September 09, 2017 \\
\hline 4 & Brgy. 396 & 4 & September 09, 2017 \\
\hline 5 & Brgy. 397 2017 \\
\hline 6 & Brgy. 404 & 4 & September 15, 2017 \\
\hline 7 & Brgy. 404 & 5 & September 15, 2017 \\
\hline 8 & Brgy. 403 & 4 & September 18, 2017 \\
\hline
\end{tabular}

\section{Respondents of the study}

The participants of the study were the 7 chairperson, 3 barangay councilors, and randomly selected residents of the ten barangays in the U-Belt Area. Ten barangay chairpersons and several barangay councilors were asked about the solid waste management programs implemented by their respective barangays and the problems they encountered during the implementation of the said program in an in-depth interview. The councilors interviewed in this study were the heads of the committee on health and sanitation.

Selected residents were asked about their awareness on solid waste management programs of their respective barangays and their recommendations for effective implementation of the said programs during the small-group discussion (SGD).

\section{Research instruments}

Two research instruments were used to gather the data needed in this study. These instruments were the interview guide questions for in-depth interview and guide questions for small group discussion. The contents of these instruments were validated by the experts in the field of research and solid waste management.

\section{Data collection procedure}

In order to gather the data needed for the study, the researchers did an in-depth interview with the barangay chairpersons and barangay councilors, focus-group discussion with the randomly selected residents, and regular observation was also conducted to validate the results. The methods in the in-depth interview and small group discussion were patterned from the suggestions of Yukalang et al. [7]. The items in the questionnaires were based from the ideas of Yukalang et al. [9] and McAllister [10].

\section{In-depth interview}

An in-depth interview with eight barangay captains, 1 barangay councilor, and 1 barangay secretary was conducted by the researchers to determine the solid waste management programs implemented by the barangays around the U-Belt area and the problems encountered by the communities in the process of implementation of the said programs. The researchers prepared the guide questions for interview ahead of time. The guide questions were validated by the expert in the field of research and environmental issues and concerns. The English version of the guide questions was translated into Tagalog so that the respondents can understand better and they can freely engage in the conversation. The researchers asked permission to record the conversations from the barangay captains, barangay councilor, and barangay secretary. Field notes were also utilized to record pertinent information during the interview.

\section{Small group discussion}

Eight small group discussions were conducted during the duration of the study. The number of participants and date of discussion in the selected barangays in the U-Belt areas during the discussion are reflected in Table 1 . The demographic profile of the participants such as age, occupation, and highest educational attainment were noted during the onset of the activity. Each participant was asked regarding his/her awareness about the implemented solid waste management programs in his/her barangay.

\section{Observation}

In order to counter-check the information disclosed by the barangay chairpersons and councilors, regular observations were conducted by the researchers. A weekly observation on the implementation of the solid waste management programs and the difficulties associated with the implementation of these programs was done from March to September 2017.

\section{Data analysis procedure}

After the collection of data, the data gathered were analyzed using descriptive statistical tools and thematic analysis. The quantitative data were interpreted using the descriptive statistical tools such as frequency counts and relative frequency. Meanwhile, the qualitative data were analyzed using thematic analysis. In this method, patterns or themes within data were identified, analyzed, and reported [7]. Patterns across data sets that are important to the description of a phenomenon and are associated to a specific research questions are referred as themes [11]. The themes generated from the data were validated by the experts in the field of research and solid waste management.

\section{Results and Discussions}

\section{Solid waste management programs in the U-belt areas}

Results of the in-depth interview indicated that the programs implemented by ten barangays in the U-Belt areas are categorized into educational, infrastructure, waste reduction, and regular cleaning activity (Figure 5). Under educational programs, barangays implemented waste segregation campaign and information campaign. Also, they strictly imposed the "No segregation, No 
Collection Policy." They also conducted the massive information campaign about proper ways of segregating of the waste materials as mandated by Republic Act 9003 . Barangays are actively allotting budget for infrastructure which will counter the disaster which may be brought about by improper solid management. They have been allocating budget for repairing drainage system and constructing material recovery facilities. Material recovery facility serves as an area to store non-biodegradable materials prior to disposal.

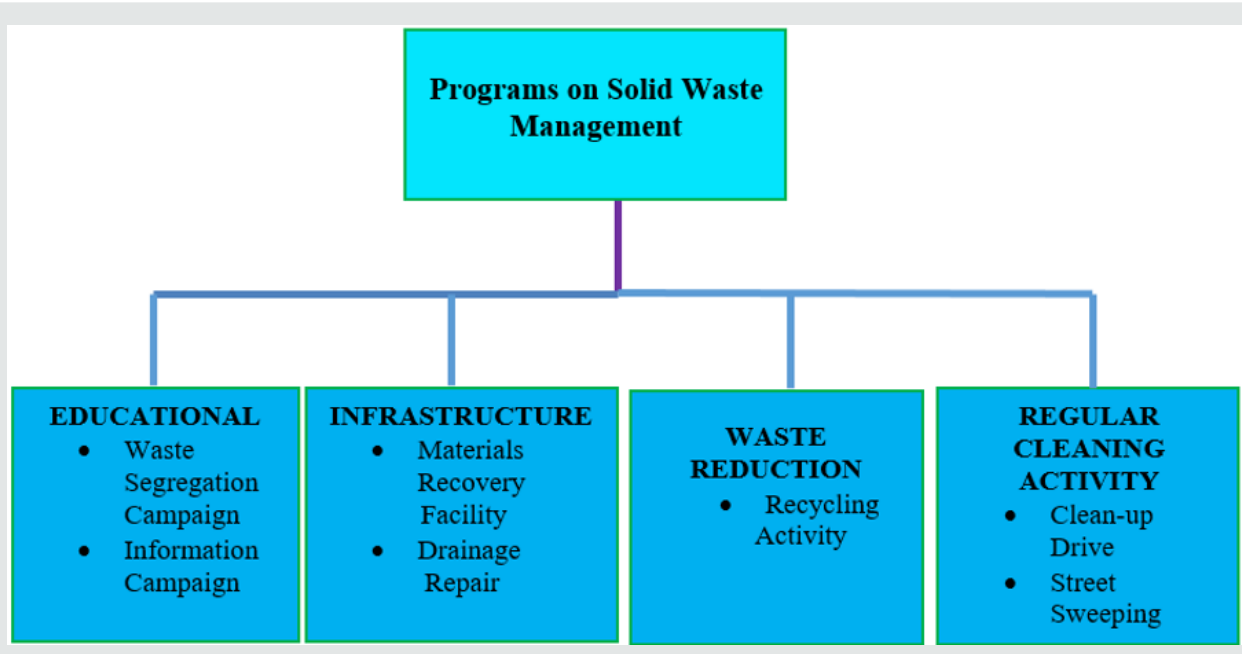

Figure 5: Categories of the Programs on Solid Waste Management in the University Belt Areas.
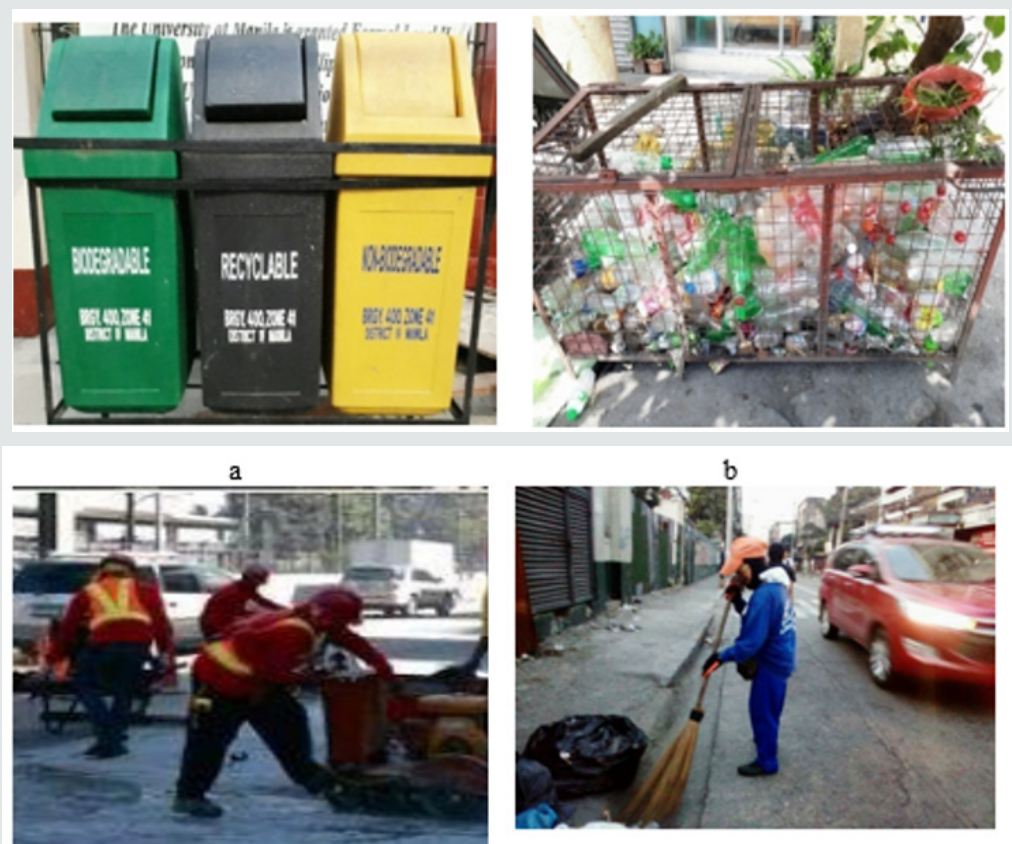

c

d
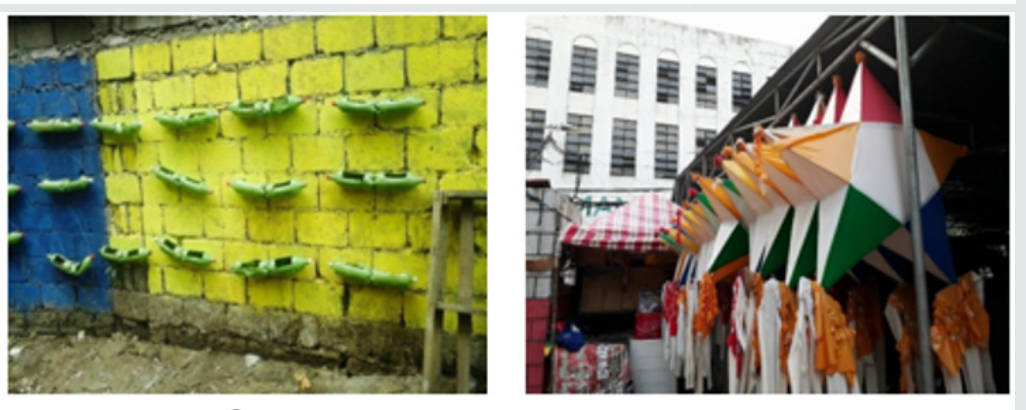

f

Figure 6: Solid Waste Management Programs in the U-Belt Area as Observed by the Researchers: a) Using Bins for Waste Segregation b) Material Recovery Facility for Storing Recycled Products c) Drainage Repair and Maintenance (Source: http:/ / opinion.inquirer.net/91905/easing-manila-traffic-congestion) d) Regular Street weeping Activity e) Using Plastic Bottles for Planting Vegetables f) Lantern Made from the Solid Waste Materials. 
In terms of waste reduction, barangays are now passionate in campaigning for the recycling activities. They encourage their residents to turn waste materials to raw materials for producing valuable products like lanterns and decorative stuffs. Regular cleaning activity, such as regular clean-up drive and street sweeping has been practiced by the local government units (LGUs) as a support to the solid management programs. The specific programs implemented ten barangays in the U-Belt areas is indicated in Table 2. Findings showed that out of ten barangays, seven of them, excluding barangays 395, 398 and 401 are currently implementing the clean-up drive program in their areas. Interestingly, ten barangays practice waste segregation program
(Figure 6a). In addition, it was also revealed e that barangays 395, 396, 398 and 402 are implementing the Materials Recovery Facility (MRF) program (Figure 6b). Moreover, the results showed that barangays 395, 396, 397, 399 and 400 are active in implementing the information campaign program concerning the battle against solid waste. Barangay 400 is the sole barangay which is regularly doing drainage maintenance (Figure 6c). Findings also showed that all the barangays in the U-Belt are currently implementing a daily street sweeping activity (Figure 6d) in their barangays. Barangays 400 and 402 are the only barangays which are implementing the recycling activities in the University Belt (Figure 6e \& Figure 6f).

Table 2: Specific solid management programs implemented by each barangay in the University Belt Area, Manila, Philippines.

\begin{tabular}{|c|c|c|c|c|c|c|c|c|}
\hline \multirow[b]{2}{*}{ Barangay } & \multicolumn{7}{|c|}{ PROGRAMS } & \multirow[b]{2}{*}{$\begin{array}{l}\text { Relative } \\
\text { Frequency }\end{array}$} \\
\hline & $\begin{array}{l}\text { Clean-up } \\
\text { Drive }\end{array}$ & $\begin{array}{c}\text { Waste } \\
\text { Segregation } \\
\text { Campaign }\end{array}$ & $\begin{array}{c}\text { Street } \\
\text { Sweeping }\end{array}$ & $\begin{array}{c}\text { Materials } \\
\text { Recovery } \\
\text { Facility }\end{array}$ & $\begin{array}{c}\text { Information } \\
\text { Campaign }\end{array}$ & $\begin{array}{c}\text { Drainage } \\
\text { Repair }\end{array}$ & $\begin{array}{l}\text { Recycling } \\
\text { Activity }\end{array}$ & \\
\hline 395 & & $\checkmark$ & $\checkmark$ & $\checkmark$ & $\checkmark$ & & & $57.14 \%$ \\
\hline 396 & $\checkmark$ & $\checkmark$ & $\checkmark$ & $\checkmark$ & $\checkmark$ & & & $71.43 \%$ \\
\hline 397 & $\checkmark$ & $\checkmark$ & $\checkmark$ & & $\checkmark$ & & & $57.44 \%$ \\
\hline 398 & & $\checkmark$ & $\checkmark$ & $\checkmark$ & $\checkmark$ & & $\checkmark$ & $71.43 \%$ \\
\hline 399 & $\checkmark$ & $\checkmark$ & $\checkmark$ & & & & & $43.86 \%$ \\
\hline 400 & & $\checkmark$ & $\checkmark$ & & $\checkmark$ & $\checkmark$ & $\checkmark$ & $71.43 \%$ \\
\hline 401 & & $\checkmark$ & $\checkmark$ & & & & & $28.87 \%$ \\
\hline 402 & $\checkmark$ & $\checkmark$ & $\checkmark$ & $\checkmark$ & & & & $57.44 \%$ \\
\hline 403 & $\checkmark$ & $\checkmark$ & $\checkmark$ & & & & & $43.86 \%$ \\
\hline 404 & $\checkmark$ & $\checkmark$ & $\checkmark$ & & & & & $28.57 \%$ \\
\hline $\mathrm{N}=10$ & $60 \%$ & $100 \%$ & $100 \%$ & $40 \%$ & $50 \%$ & $10 \%$ & $20 \%$ & \\
\hline
\end{tabular}

Over the years rapid urbanization is taking place in Manila City, Philippines. This phenomenon was due to economic and social reasons. Consequently, the amount of waste materials generated also increases. Bernardo [12] showed that the households in the city generated an average of $3.2 \mathrm{Kg}$ of solid waste per day, or $0.50 \mathrm{Kg} /$ capita/day. In 2010, the estimated amount of solid waste generated in Manila was 2,990,814 metric tons and it increased to 3,595, 593 metrics in 2014 [4]. The existence of the different programs on solid waste management in ten barangays in the U-Belt area are the response of the various communities to the alarming problems associated with the elevating amount of solid waste generated in the congested communities. These programs are the manifestations that these barangays are abiding to the important provisions stipulated in Republic Act 9003, otherwise known as the "Philippine Ecological Solid Waste Management Act of 2000.

\section{Awareness of the residents on solid waste management programs}

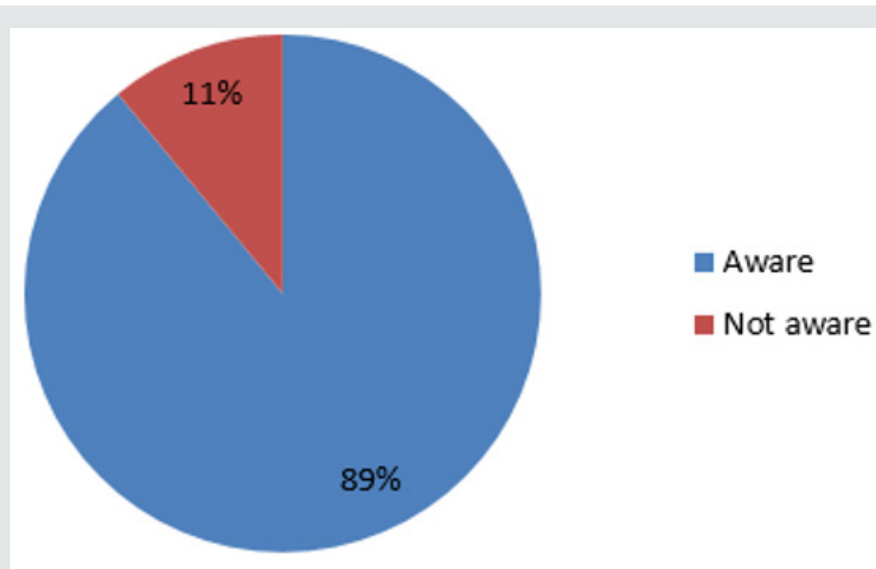

Figure 7: Distribution of awareness of the selected residents about programs on solid waste management. 
During the SGD, all participants were asked about their awareness on the programs implemented by the barangays in the U-Belt area on solid waste management. Findings of the investigation showed that $89 \%$ (31) of the participants are aware about the programs while $11 \%$ (4) participants are unaware (Figure 7). Generally, the results manifest that most of them have an idea about the implementation of the aforementioned programs. Awareness of the people about the programs is the outcome of the massive information drive and visibility of the infrastructure projects of the local government units. The high percentage of awareness on solid waste management programs among the residents in the U-Belt barangays is an indication that people are vigilant and participative in the programs and projects of the communities. Their participation ranges from attending the general assembly of the barangays up to abiding the proper segregation policy. On the hand, there are residents that remain not ware about the programs and policies of the barangays on solid waste management. Perhaps, they are not watchful regarding what is going to their communities and at the same time they are not participative to the activities of their barangays.

\section{Constraints on solid waste management}

Constraints encountered in the course of the implementation of every project and program makes the implementation itself very challenging. The problems encountered by the barangays in the U-belt areas in the implementation of the solid waste management programs are given in Figure 8. Findings showed that all ten barangays are currently facing the problem on the lack of discipline among the residents. They throw their garbage anywhere. They are particular of the designated places for their waste materials. Barangay 399 and Barangay 404 consider deficiency of funds as a major problem in the implementation of the program on solid waste management. Furthermore, it is also indicated above that 7 out of 10 barangays except for barangays 399, 402 and 403 are experiencing problem in terms of irregular collection of wastes. Findings also show that the barangays 395 and 397 are facing a problem on their location, which causes these barangays to produce more solid waste materials.

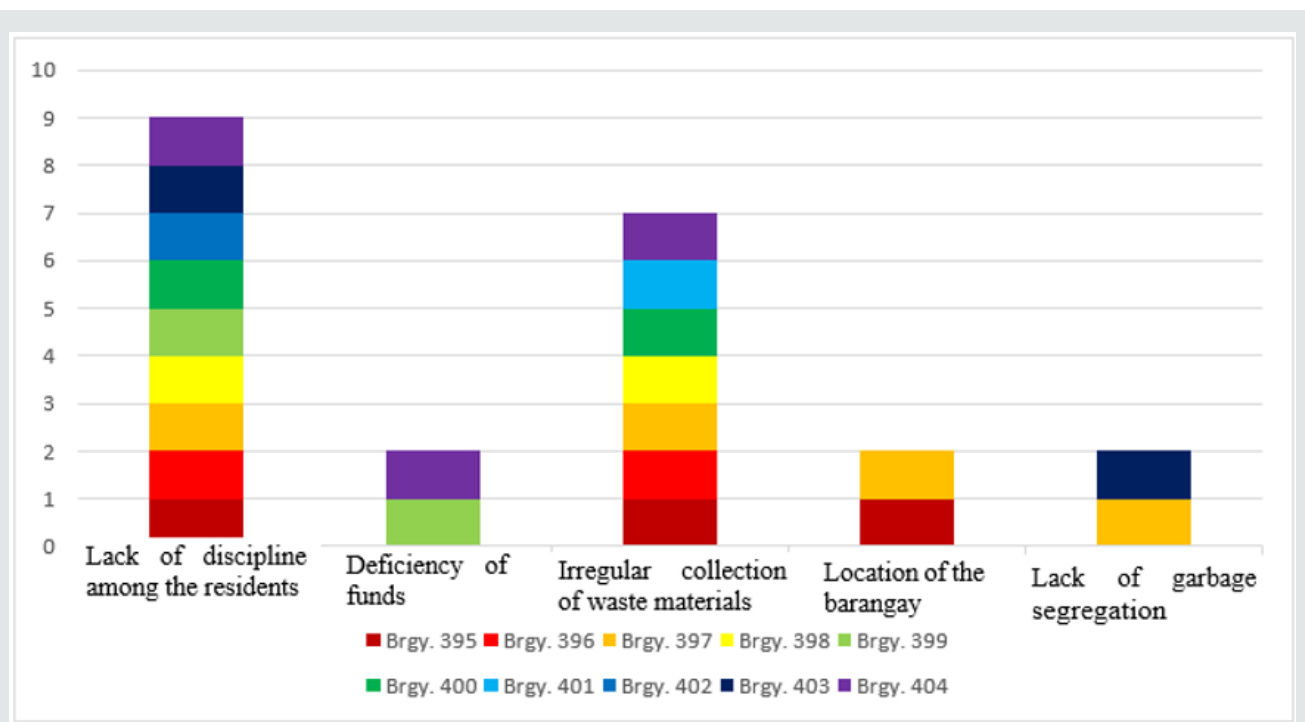

Figure 8: Problems encountered by the barangays in the U-belt areas in the implementation of the solid waste management programs.

The constraints experienced by the U-Belt barangays in connection with the implementation of solid waste management programs in their communities are typical issues observed also in the other urbanized cities in the Philippines. For instance, Reyes \& Arturo [13] observed several problems encountered by the community people in the implementation of solid waste management practices in the different barangays in Batangas City, Philippines. In their study, they found that the increasing population, inadequate government policies, public indifference (public don't care), inefficient collection of garbage, rapid urbanization, non-operation of a good disposal facility, irresponsible government officials, lack of awareness among the people regarding the effects of solid waste management practices to their health and the environment, and lack of training on proper solid waste management practice are major barriers in implementing effective and efficient solid waste management programs.
In the developing countries however, there are constraints associated with solid waste management implementation. These constraints are categorized into culture, education, and microeconomics; infrastructure and technology; and policy, institutions, and macroeconomics [10]. In terms of culture, education, and microeconomics, the major constraints comprise the attitude and behavior gap of the people and lack of campaign on education and awareness. Major constraints under infrastructure and technology include budgetary constraints, inadequate service and operational inefficiencies, ineffective technologies and equipment inadequacy, lack of landfill disposal, and limited utilization of waste reduction activities. Under policy, institutions, and macroeconomics, the major constraints encompass lack of policy, poor enforcement and responsibility, and lack of monitoring and regulation. 


\section{Recommendations of the residents for effective implementation of solid waste programs}

Some of the programs on solid waste management are not effectively implemented due to the political, educational, and socio-economic reasons. During the focus group discussion, the residents suggested some recommendations to the barangay officials for effective and efficient implementation of the solid waste management programs in the U-Belt Areas. These include implementation of the appropriate barangay resolutions, raising public awareness, and imposition of penalties for the violators.

\section{Implementation of the appropriate barangay resolutions}

One of the best strategies in order to ensure the effective implementation of the solid waste programs is to pass the appropriate barangay resolutions. The residents said that the existing resolutions are not enough to support the implementation of the aforementioned programs. Hence, the barangay council needs to pass some additional resolutions aside from "No Segregation; No Collection Policy." These resolutions once passed should be disseminated to the general public. According to the respondents, in order for the residents to become fully aware of these resolutions, the council should ensure maximum attendance of the residents during the barangay assembly. In the era of rapid urbanization in the cities of the third world countries (e.g. Manila), appropriate policies should be implemented to address the problems associated with high urbanization growth [14]. In the case of the barangays in the U-Belt Areas, in order make solid waste management programs effective the policies and resolutions that may focus on allotting budget for the implementation of the programs, improving the linkages to the non-governmental organizations (NGOs), private sectors, and cause-oriented groups and proper spatial planning.

\section{Raising public awareness}

The success of the programs and projects on solid waste management strongly depends on the support of the stakeholders and the general public. The participation of these groups of people can be maximized if they have been properly informed. As revealed by the residents, the barangay should boost the awareness of the people through educational campaign and massive public information dissemination drive. The campaign for solid waste management programs in the U-Belt area can be disseminated well through posting in the bill boards and other public places. Campaign can be done during the barangay assembly; hence, the barangay officials should ensure the maximum attendance of the residents. Cultural and literary programs through songs and poetry can also be explored in order to boost the awareness of the people thriving in the U-Belt Area.

\section{Imposition of penalties for the violators}

According to the participants in the SGD, there is a need to impose penalties to the violators in order to make implementation of the solid waste management more effective. Violators, in the context of this study; refers to the residents who are not abiding with the policies and resolutions about management of solid waste. For instance, these people don't dump their garbage materials in the right bins and throw their waste materials in bodies of water. Those who are doing such should be penalized by the barangay councils. The penalty could be letting them engage on community service or pay offenders can pay a certain amount of money. Community service, on the other hand, could include cleaning the public places such plaza, streets, and bodies of water and repairing of the drainage system. Imposing these types of penalties will create a culture of discipline and support among the residents.

The success of the implementation of solid waste management can be attributed by three major factors. These factors include people's orientation and strong political leadership, strong collaboration among the different sectors of the community, mass information, education, and communication campaign, and linkage and networking with different agencies and organizations $[15,16]$. Mc Allister [10] considered potential interventions in order to implement solid waste management programs effectively and efficiently. These interventions include intensified education and awareness campaign, enhancement of public participation, promotion of the incentive scheme, improvements in service operations, improvements in the accessibility of the technologies, utilization of the recycling initiatives, improvements in disposal system, creation of landfill, enhancement in the funding management, and proper enactment and enforcement of the policies and programs.

\section{Conclusion}

The programs implemented by ten barangays in the U-Belt areas are categorized into educational, infrastructure, waste reduction, and regular cleaning activity. These programs are known to most residents of the area. In the process of implementation, the LGUs are facing some constraints. These constraints are: lack of discipline of among the residents: lack of funds: irregular collection of waste; location of the barangay; and lack of segregation. To effectively implement the aforementioned programs, the residents suggested some important recommendations. These include implementation of the appropriate barangay resolutions, raising public awareness, and imposition of penalties for the violators (Figure 9).

Furthermore, the concept of eco-city $[17,18]$ should be integrated by the U-Belt barangays in their campaign for effective solid waste management programs. The idea of composting [19] in the urban setting like enzyme-enhanced compositing and vermicomposting [20-24] should also be considered for the aforementioned program. For the future research endeavor, a greater number of respondents should be considered. Hence, the entire University Belt area should be covered in the succeeding research activity. From the major findings acquired in this study, the authors came up with the extension program of SHS Department of UE Manila known as "FERRIS WHEEL PROJECT" (Figure10). It is a holistic, multi-sectoral, and multi-disciplinary project which aims to further raise the awareness of all sectors in the U-Belt community about problems associated with solid waste management. These sectors include business, youth, local government unit, academe, and people with disabilities. 


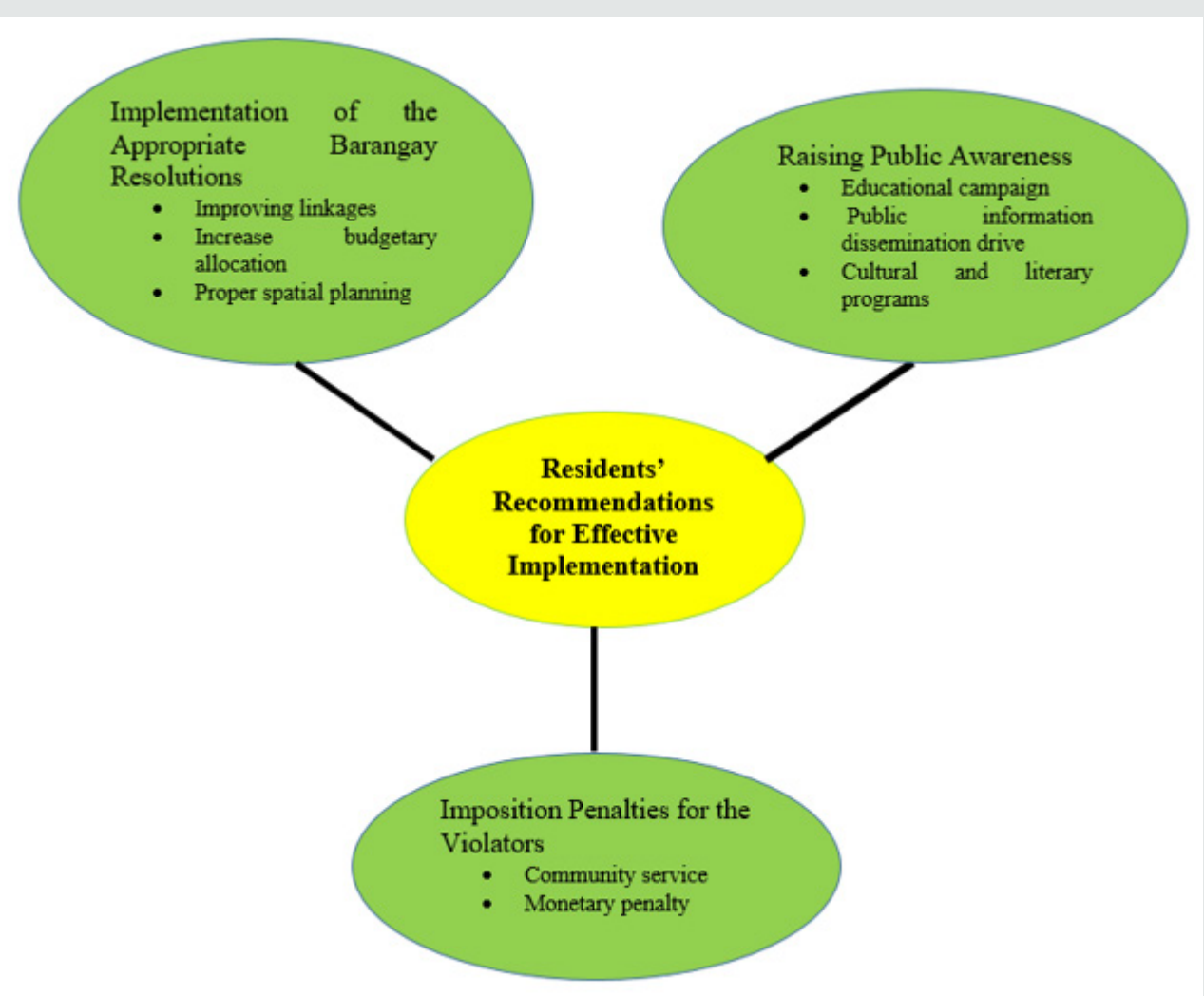

Figure 9: Residents' Recommendations for Dynamic Solid Waste Management Program.

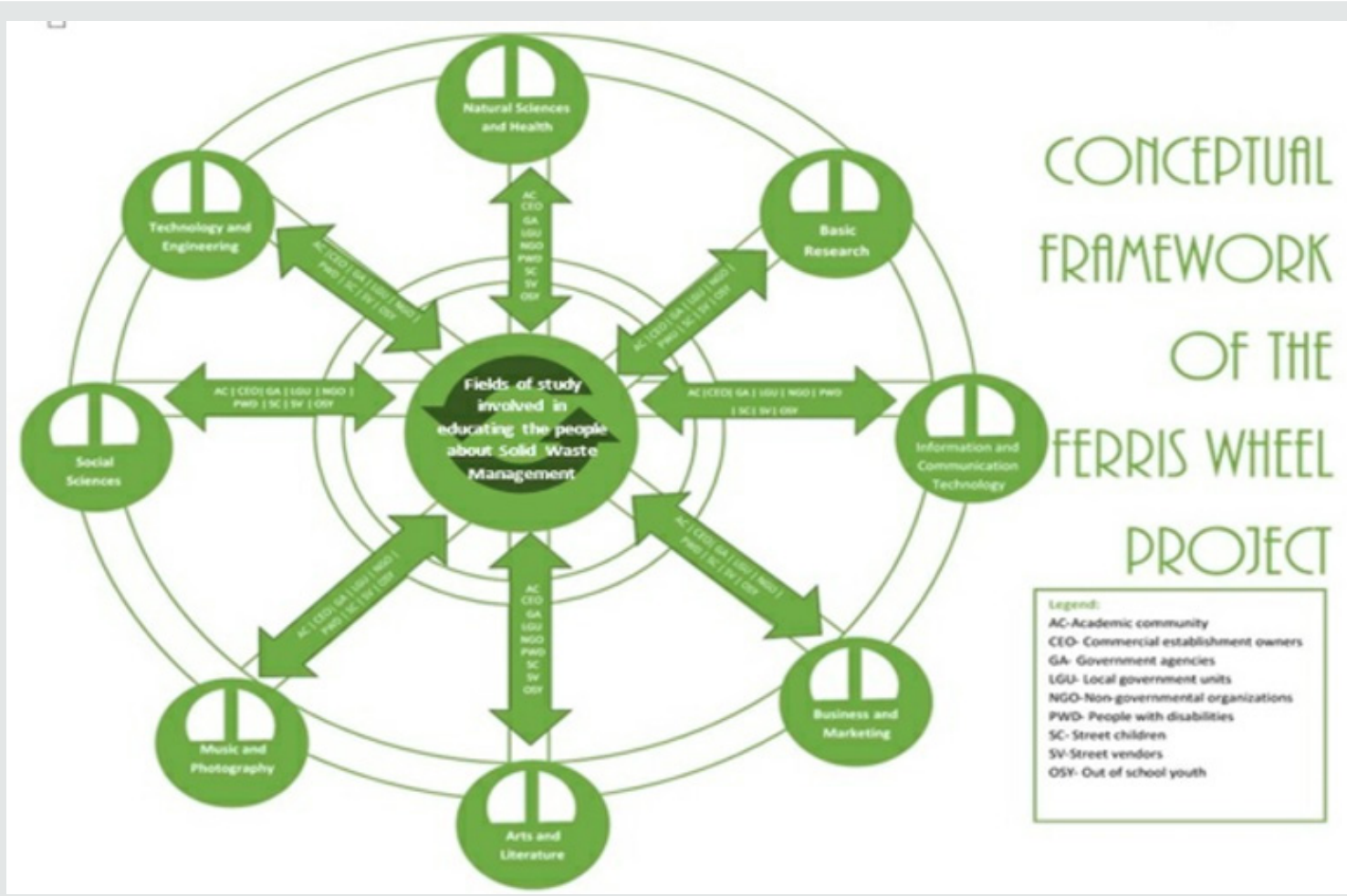

Figure 10: Conceptual Framework of Ferris Wheel Project (Illustrated by Asst. Prof. Dannah Ramos in collaboration with Asst. Prof. Vina Marie Suyu and Asst. Prof. Dustyne Dimaguila with the idea of Asst. Prof. Raymund Fantonalgo).

\section{Acknowledgement}

The authors would to like to thank the technical expertise of Prof. Mayflor M. Tacardon for validating the instruments and providing us the idea how to present the data gathered and Madam
Juliet Salubre, Solid Waste Management Officer, Environmental Management Bureau (EMB) of Department of Environment and Natural Resources (DENR) VI, Philippines for validating the questionnaires and the themes generated from this study. 
Gratitude is extended to all barangay captains of the U-Belt area for allowing us to conduct study in their areas of jurisdiction. We are also grateful to all barangay councilors in the areas for sharing their ideas about the solid waste management programs of the U-Belt area and the selected residents of the participating barangays for joining the small group discussion and sharing some information related to the topics of this investigation. We would like also to thank for the moral, intellectual, and financial support of Senior High School Department of University of the East-Manila, Philippines for making this study a productive one.

\section{References}

1. United Nations, Department of Economic and Social Affairs, Population Division (2014). World Urbanization Prospects: The 2014 Revision, Highlights (ST/ESA/SER.A/352).

2. Henderson V (2002) Urbanization in Developing Countries. The World Bank Research Observer 17(1): 89-112.

3. Mohammed YA (2016) Cause and Consequence of Cross Border Illegal Migration from South Wollo, Ethiopia. Arts Social Sci J 7(2): 1-20.

4. (2017) National Solid Waste Management Commission Reports, 2015 National Solid Waste Management Status Report (2008-2014).

5. Haase D (2009) Effects of urbanisation on the water balance-A long-term trajectory. Environmental Impact Assessment Review 29(4): 211-219.

6. Discipulo NJ (2012) Culture Revitalization in the Central University Belt (CUBE): An Educational Process Towards Urban Renewal. Philippines.

7. Braun V, Clarke (2006) Using thematic analysis in psychology. Qualitative Research in Psychology 3: 77-101.

8. Shields P, Rangarajan N (2013) A Playbook for Research Methods: Integrating Conceptual Frameworks and Project Management. New Forums Press, Stillwater, Oklahoma, USA.

9. Yukalang N, Clarke B, Ross K (2017) Barriers to Effective Municipal Solid Waste Management in a Rapidly Urbanizing Area in Thailand. Int J Environ Res. Public Health 14(9): 1-23.
10. McAllister J (2015) Factors influencing solid waste management in the developing world. All graduate Plan B and other reports. pp. 528.

11. Daly K, Gliksman K (1997) The public health researcher: A methodological approach. Oxford University Press, Melbourne, Australia, pp. 611-618.

12. Bernardo EC (2008) Solid-waste management practices of households in Manila, Philippines. Ann N Y Acad Sci 1140: 420-424.

13. Reyes PB, Furto MV (2013) Greening of the Solid Waste Management in Batangas City. Journal of Energy Technologies and Policy 3(11): 187194.

14. Hope KR (1986) Urbanization and economic development in the Third World. Cities 3(1): 41-57.

15. Atienza VA (2008) Breakthroughs in solid waste management: Lessons from selected municipality and barangay in the Philippines. Asian Review of Public Administration 10(1-2) 82-98.

16. Atienza VA (2008) A breakthrough in solid waste management through participation and community mobilization: The Experience of Los Baños, Ritsumeikan Asia Pacific University, Laguna, Philippines.

17. Register R (2002) Ecocities: Building cities in Balance with Nature. New Society Publishers. Republic Act 9003.

18. Huang SL, Yeh CT Chang LF (2010) The transition to an urbanizing world and the Demand for natural resources. Current Opinion in Environmental Sustainability 2(3): 136-143.

19. Atega MJ, Jardeleza R, Castillo CJ, Gumabon LV, Fantonalgo R, et al. (2017) Perception of Selected Residents on Household Composting in Highly Urbanized Area,Manila, Philippines, 2(4): 1-10.

20. Fantonalgo RN, Salubre JG (2019) Using Sargassumoligocystum and kitchen waste for vermicast production: A comparative study. Springer.

21. Map of the Philippines.

22. Map of Manila City.

23. Vicinity Map of University Belt Area.

24. Map of the U-Belt Area.

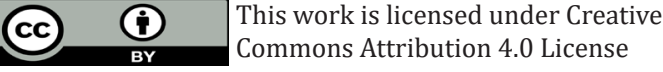

To Submit Your Article Click Here:

Submit Article
DOI: $10.32474 /$ OAJESS.2019.03.000151

Citation: Fantonalgo RN, Failanga JN, Argañosa MH, Bautista RIT, Fajardo RL, et al,. Battle Against Solid Waste: Contribution of University Belt Barangays Towards Clean and Disaster-Prepared City. Open Acc J Envi Soi Sci 3(1)-2019. OAJESS.MS.ID.000151. D0I: 10.32474/ OAJESS.2019.03.000151

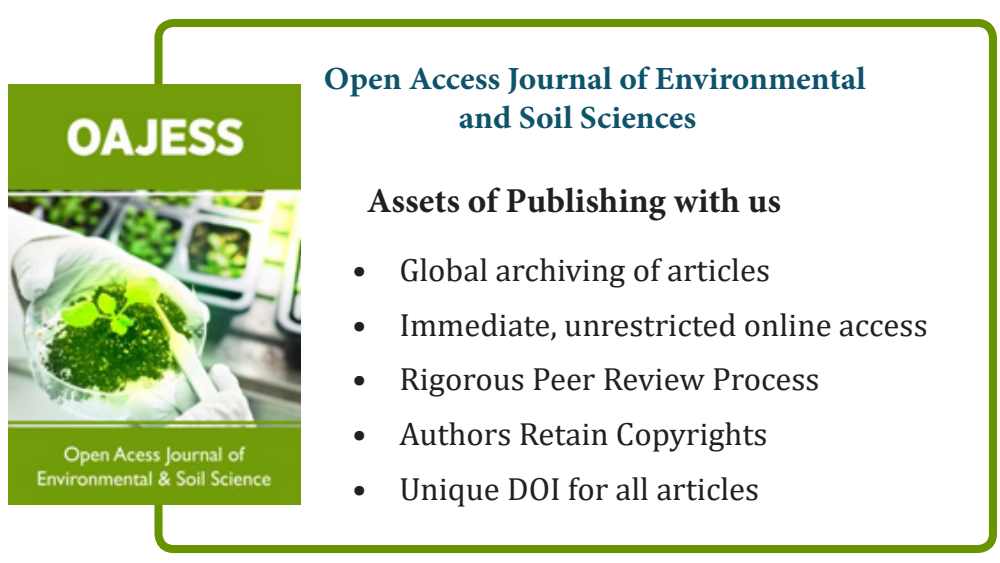

